\title{
Influences of income and employment on psychological distress and depression treatment in Japanese adults
}

\author{
Yoshiharu Fukuda • Ayako Hiyoshi
}

Received: 5 December 2010/ Accepted: 18 February 2011/Published online: 16 March 2011

(C) The Japanese Society for Hygiene 2011

\begin{abstract}
Objectives Psychological distress is a health issue of critical importance, especially in people of working age in developed countries, including Japan. This study examined the relationships of income and employment arrangement with psychological distress and treatment of depression in a national sample of Japanese adults.

Methods Data for 10,959 men and 11,655 women 25-59 years of age, obtained from the Comprehensive Survey of the Living Conditions of People on Health and Welfare in 2007, were examined. Health outcomes were psychological distress measured by the Japanese version of the K6, subjective complaints and medical treatment of depression. Explanatory variables included marital status, employment arrangement, and household income. The relationships between health outcomes and explanatory variables were examined using multiple logistic regression analyses.

Results Lower income and unemployment were associated with a higher prevalence of psychological distress and treatment of depression. The association between psychological distress and income showed a threshold: the lowest income quintile had an especially high prevalence, while other quintiles had similar prevalences. The prevalence of depression treatment in those with psychological distress
\end{abstract}

\section{Y. Fukuda $(\square)$}

Department of Community Health and Medicine,

Yamaguchi University School of Medicine,

1-1-1 Minami Kogushi, Ube,

Yamaguchi 755-8505, Japan

e-mail: fukuday@yamaguchi-u.ac.jp

A. Hiyoshi

Department of Epidemiology and Public Health,

University College London, London, UK was significantly lower in the highest income quintile than in all the other income groups, and the prevalence was also significantly lower in employed than in unemployed respondents.

Conclusions This study showed clear relationships of lower income and unemployment with psychological distress and depression treatment. It has been suggested that people with higher socioeconomic status and full-time work may be reluctant to consult professionals and receive medical treatment, despite their psychological distress. Comprehensive mental health interventions are required to prevent psychological distress in all socioeconomic strata of the population.

Keywords Psychological distress - Mental health · Socioeconomic status (SES) - Depression · Work

\section{Introduction}

Mental health and psychological disorders are among the most important health issues in developed countries, including Japan. Depression is the fourth leading cause of disease burden, accounting for $4.4 \%$ of total disabilityadjusted life years (DALYs ) worldwide in 2000 [1]. In Japan, suicide is the seventh leading cause of death, accounting for more than 30,000 deaths annually [2], and depression, in addition to social and environmental factors, plays a critical role in the etiology of suicide [3, 4]. Although the results are not conclusive as yet, the influences of the recent economic recession and overwork on general and mental health are issues of concern $[5,6]$.

Social epidemiology is the branch of epidemiology that studies the social distribution and social determinants of states of health [7]. One major aspect of social 
epidemiology is work and health, focusing on health inequalities resulting from specific occupations and the health effects of working conditions and job loss [8]. Previous studies have examined work stress and health using theoretical frameworks such as the demand-control model and the effort-reward imbalance model $[8,9]$. Other studies have demonstrated that socioeconomic status (SES), measured by income and educational level, affects health as a factor modifying the associations between work stress and health $[10,11]$.

Most previous studies showed that people with lower SES, measured by parameters such as educational and income level, had a higher prevalence of psychological distress [12-14], and similar relationships were found in studies of the Japanese population $[15,16]$. However, at the same time, these findings suggested that the SES-psychological distress relationship may be complex. For example, men with higher SES are more vulnerable to interpersonal conflict at work, with the associated development of depression, than men with lower SES [15]. Despite the importance of this issue, there is little evidence of the impacts of work and SES on psychological distress or on medical treatment for such distress in the general population in Japan.

This study examined the relationships of income and employment arrangement with psychological distress and the treatment of depression in a national sample of Japanese adults.

\section{Subjects, materials, and methods}

Data and study population

Data from the 2007 Comprehensive Survey of the Living Conditions of People on Health and Welfare conducted by the Ministry of Health, Labour and Welfare [17] were analyzed. This survey commenced in 1986, and an extensive survey is conducted every 3 years (demography, health, long-term care, income, and savings). In the 2007 survey, 5,440 enumeration districts (EDs) from among approximately one million EDs were randomly selected for questionnaires on demography and health. Interviewers visited all households in the selected areas, using lists of households, and approached all household members. The questionnaires consisted of household and individual basic information on demographics, health, illness profiles, lifestyle, and other items. Further, 2,000 unit areas were randomly selected from among the 5,400 EDs, and all households and household members were approached to answer questionnaires on income and savings.

The health-related questionnaires included the Japanese version of the K6, with questions on subjective complaints and treatment. The K6 consists of six questions that assess depressive mood and anxiety during the preceding 1 month, using answers on a 5-point scale ranging from "none" to "very much" [18, 19]. The questionnaire on subjective complaints involved first asking "Do you have any types of physical complaints?", and, if the subject answered "yes", selecting the complaints from among 41 items. The questionnaire on treatment started by asking "Do you receive any type of outpatient treatment?", and, if the subject answered "yes", selecting the diseases and physical conditions from among 39 items. Treatment facilities included not only traditional medical facilities (hospitals and clinics) but also those providing acupuncture and osteopathy.

The total number of households sampled for basic information was 287,807 , of which 36,285 were interviewed with regard to income and savings. The response rates were $80.1 \%(N=230,596)$ for the basic information survey and $67.7 \%(N=24,578)$ for the income survey. Numbers of household members ranged from 1 to 13, with a mean (SD) of 2.7 (2.2). We used the data for 10,959 men and 11,655 women 25-59 years of age, for whom basic and income data were surveyed and for whom there were no missing data for variables analyzed in this study.

Micro-data files from this survey were used with permission from the Ministry of Health, Labour and Welfare.

\section{Outcome variables}

Psychological distress and depression treatment were used as health outcome variables. Psychological distress was measured using the Japanese version of the K6 and psychological complaints. The K6 was scaled using six questions on a 5 -point scale (none $=0$ to very much $=4$ ) [18, 19]. The sum of six item scores (ranging from 0 to 24) was used to indicate the degree of depression and anxiety. In this study, two cut-off scores were used, 5 and 13, in accordance with prior studies [16, 19], and a higher score meant more severe distress. Psychological complaints were defined as the subjects having at least one complaint of "general fatigue", "sleeplessness", or "irritation". Finally, treatment for depression and other mental disorders served as the "depression treatment" variable.

\section{Explanatory variables}

Age, marital status, employment arrangement, and household income were used as possible explanatory variables for psychological distress and depression treatment. Marital status was divided into three categories: married, never married, and separated or divorced. Employment arrangement was divided into five categories: employed (mainly working), housework with employment, housework 
without employment, unemployed, and others, including student and unknown status. Information on annual household income before taxes, including benefits and inheritance, was used as the income measure, and the study subjects were divided into quintiles according to household income. The 1 st through 5 th quintiles corresponded to the lowest through highest incomes.

\section{Statistical analysis}

The prevalences of psychological distress and depression treatment were computed employing possible explanatory variables. The prevalence of depression treatment in respondents with psychological distress and the prevalence of psychological distress in those receiving depression treatment were also calculated. Finally, multiple logistic regression analysis was used to calculate an adjusted odds ratio (aOR) with $95 \%$ confidence interval (95\% CI). The outcome variables were K6 5+, K6 13+, psychological complaints, depression treatment, depression treatment in respondents with psychological distress, and psychological distress in respondents receiving depression treatment. The explanatory variables were age, sex, marital status (reference $=$ married), employment arrangement (reference $=$ employed), and household income (reference $=$ 5th quintile). The statistical package PASW Statistics 18 (SPSS, Chicago, IL, USA) was used for all analyses.

\section{Results}

Table 1 summarizes the basic characteristics and the prevalences of psychological distress and depression treatment. The number of women was slightly larger than that of men, and the majority of the subjects were married (72.4\%) and employed (70.9\%). The prevalences of 5+ in K6, $13+$ in K6, having a psychological complaint, and depression treatment were $30.6,4.2,9.5$, and $1.7 \%$, respectively. Mean household annual incomes by quintiles are also shown in Table 1. The cut-offs for the quintiles were 10.3, 7.5, 5.5, and 3.6 million yen.

Cross-tabulations for psychological outcomes and explanatory variables are shown in Table 2 . The lowest prevalences of all four psychological outcomes were commonly found in married and employed respondents. As to household income, the lowest quintile showed the highest prevalence of all four psychological outcomes, but there was no clear gradient from the 5th (highest) to the 2nd (2nd lowest) quintile. Because of the large sample size, most of the relationships showed statistical significance $(p<0.05)$ by the $\chi^{2}$ test.

Table 3 shows the results of the multiple logistic regression analysis, i.e., aORs and their 95\% CIs for
Table 1 Summary of sociodemographic characteristics and psychological outcomes

\begin{tabular}{|c|c|}
\hline & $N(\%)$ \\
\hline Age (years) & $43.6 \pm 10.2^{\mathrm{a}}$ \\
\hline \multicolumn{2}{|l|}{ Sex } \\
\hline Male & $10,959(48.5)$ \\
\hline Female & $11,655(51.5)$ \\
\hline \multicolumn{2}{|l|}{ Marital status } \\
\hline Married & $16,368(72.4)$ \\
\hline Never married & $4,787(21.2)$ \\
\hline Separated/divorced & $1,459(6.5)$ \\
\hline \multicolumn{2}{|l|}{ Employment arrangement } \\
\hline Employed (mainly working) & $16,041(70.9)$ \\
\hline Housework with employment & $2,169(9.6)$ \\
\hline Housework without employment & $3,127(13.8)$ \\
\hline Unemployed & $933(4.1)$ \\
\hline Others & $344(1.5)$ \\
\hline \multicolumn{2}{|l|}{ Household income (annual, million yen) } \\
\hline 5th quintile (highest) $(N=4,524)$ & $14.9 \pm 6.3^{\mathrm{a}}$ \\
\hline 4th quintile $(N=4,492)$ & $8.8 \pm 0.8^{\mathrm{a}}$ \\
\hline 3rd quintile $(N=4,552)$ & $6.5 \pm 0.6^{\mathrm{a}}$ \\
\hline 2nd quintile $(N=4,524)$ & $4.5 \pm 0.5^{\mathrm{a}}$ \\
\hline 1st quintile (lowest) $(N=4,522)$ & $2.3 \pm 0.8^{\mathrm{a}}$ \\
\hline Total $(N=22,614)$ & $7.4 \pm 0.5^{\mathrm{a}}$ \\
\hline \multicolumn{2}{|l|}{ K6 score (cut-off $=5$ ) } \\
\hline$<5$ & $15,685(69.4)$ \\
\hline $5+$ & $6,929(30.6)$ \\
\hline \multicolumn{2}{|l|}{ K6 score $($ cut-off $=13)$} \\
\hline$<13$ & $21,672(95.8)$ \\
\hline $13+$ & $942(4.2)$ \\
\hline \multicolumn{2}{|c|}{$\begin{array}{l}\text { Psychological complaints } \\
\text { (fatigue, sleeplessness, and/or irritation) }\end{array}$} \\
\hline No & $20,460(90.5)$ \\
\hline Yes & $2,154(9.5)$ \\
\hline \multicolumn{2}{|l|}{$\begin{array}{l}\text { Depression treatment } \\
\text { (medical treatment for depression } \\
\text { and/or other mental disorders) }\end{array}$} \\
\hline No & $22,236(98.3)$ \\
\hline Yes & 378 (1.7) \\
\hline
\end{tabular}

${ }^{a}$ Values are means $\pm \mathrm{SD}$

psychological outcomes. Three outcomes $(5+$ in K6, $13+$ in K6, and psychological complaint) showed similar results: aORs were significantly higher for women than men, never married and separated/divorced versus married, unemployed versus employed, and the lowest income quintile versus the highest income quintile. In depression treatment, aORs tended to be larger than those for other outcomes. As to household income for $5+$ in $\mathrm{K} 6,13+$ in K6, and psychological complaints, several aORs did not show significant differences as compared with the 5th (highest) quintile. However, in depression treatment, all 
Table 2 Prevalences of psychological distress and depression treatment by sociodemographic characteristics

\begin{tabular}{|c|c|c|c|c|c|}
\hline Variable & Total $N$ & $\mathrm{~K} 65+(\%)$ & K6 $13+(\%)$ & $\begin{array}{l}\text { Psychological } \\
\text { complaints (\%) }\end{array}$ & $\begin{array}{l}\text { Depression } \\
\text { treatment }(\%)\end{array}$ \\
\hline \multicolumn{6}{|l|}{ Sex } \\
\hline Male & 10,959 & $29.6 * *$ & $3.8 * *$ & $8.3 * * *$ & 1.6 \\
\hline Female & 11,655 & 31.6 & 4.5 & 10.6 & 1.8 \\
\hline \multicolumn{6}{|l|}{ Marital status } \\
\hline Married & 16,368 & $29.2 * * *$ & $3.6 * * *$ & $9.0 * * *$ & $1.2 * * *$ \\
\hline Never married & 4,787 & 33.3 & 5.3 & 10.1 & 2.7 \\
\hline Separated/divorced & 1,459 & 38.6 & 6.7 & 13.1 & 3.4 \\
\hline \multicolumn{6}{|l|}{ Employment arrangement } \\
\hline Employed (mainly working) & 16,041 & $29.6 * * *$ & $3.8 * * *$ & $8.7 * * *$ & $1.1 * * *$ \\
\hline Housework with employment & 2,169 & 31.9 & 3.8 & 9.7 & 1.2 \\
\hline Housework without employment & 3,127 & 30.8 & 4.5 & 11.5 & 2.2 \\
\hline Unemployed & 933 & 43.3 & 10.0 & 14.8 & 9.0 \\
\hline Others & 344 & 36.0 & 6.1 & 12.5 & 4.4 \\
\hline \multicolumn{6}{|l|}{ Household income } \\
\hline 5th quintile (highest) & 4,524 & $27.8 * * *$ & $3.1 * * *$ & $7.9 * * *$ & $0.8 * * *$ \\
\hline 4th quintile & 4,492 & 29.1 & 3.6 & 9.3 & 1.3 \\
\hline 3rd quintile & 4,552 & 29.4 & 3.9 & 8.9 & 1.7 \\
\hline 2nd quintile & 4,524 & 30.3 & 3.5 & 9.6 & 1.4 \\
\hline 1st quintile (lowest) & 4,522 & 36.6 & 6.6 & 11.9 & 3.1 \\
\hline
\end{tabular}

Psychological distress was measured by K6 (cut-off $=5$ or 13) and psychological complaints (general fatigue, sleeplessness, and/or irritation) $* * p<0.01, * * * p<0.001\left(\chi^{2}\right.$ test $)$

Table 3 Results of multiple logistic regression analysis for psychological distress and depression treatment

\begin{tabular}{|c|c|c|c|c|c|c|c|c|}
\hline \multirow[t]{2}{*}{ Variable } & \multicolumn{2}{|c|}{ K6 5+ } & \multicolumn{2}{|c|}{ K6 13+ } & \multicolumn{2}{|c|}{ Psychological complaints } & \multicolumn{2}{|c|}{ Depression treatment } \\
\hline & $\mathrm{aOR}$ & $(95 \% \mathrm{CI})$ & $\mathrm{aOR}$ & $(95 \% \mathrm{CI})$ & $\mathrm{aOR}$ & $(95 \% \mathrm{CI})$ & $\mathrm{aOR}$ & $(95 \% \mathrm{CI})$ \\
\hline Sex: female/male & 1.06 & $(0.99-1.14)$ & 1.17 & $(1.00-1.36)^{*}$ & 1.24 & $(1.12-1.38)^{* * *}$ & 1.00 & $(0.78-1.28)$ \\
\hline \multicolumn{9}{|l|}{ Marital status } \\
\hline Married & 1.00 & Reference & 1.00 & Reference & 1.00 & Reference & 1.00 & Reference \\
\hline Never married & 1.15 & $(1.06-1.25)^{* * *}$ & 1.26 & $(1.05-1.51)^{*}$ & 1.11 & $(0.97-1.26)$ & 1.65 & $(1.24-2.19)^{* * *}$ \\
\hline Separated/divorced & 1.35 & $(1.20-1.52)^{* * *}$ & 1.48 & $(1.17-1.88)^{* *}$ & 1.33 & $(1.12-1.58)^{* *}$ & 2.12 & $(1.50-3.01)^{* * *}$ \\
\hline \multicolumn{9}{|l|}{ Employment arrangement } \\
\hline Employed (mainly working) & 1.00 & Reference & 1.00 & Reference & 1.00 & Reference & 1.00 & Reference \\
\hline Housework with employment & 1.12 & $(1.01-1.25)^{*}$ & 1.01 & $(0.78-1.31)$ & 1.02 & $(0.87-1.21)$ & 1.18 & $(0.75-1.86)$ \\
\hline Housework without employment & 1.06 & $(0.96-1.16)$ & 1.17 & $(0.95-1.46)$ & 1.22 & $(1.06-1.41)^{* *}$ & 2.27 & $(1.63-3.15)^{* * *}$ \\
\hline Unemployed & 1.57 & $(1.37-1.80)^{* * *}$ & 2.17 & $(1.70-2.76)^{* * *}$ & 1.59 & $(1.30-1.93)^{* * *}$ & 5.85 & $(4.38-7.82)^{* * *}$ \\
\hline Others & 1.26 & $(1.01-1.58)^{*}$ & 1.45 & $(0.92-2.28)$ & 1.37 & $(0.99-1.89)$ & 3.41 & $(1.98-5.87)^{* * *}$ \\
\hline \multicolumn{9}{|l|}{ Household income } \\
\hline 5th quintile (highest) & 1.00 & Reference & 1.00 & Reference & 1.00 & Reference & 1.00 & Reference \\
\hline 4th quintile & 1.06 & $(0.97-1.17)$ & 1.16 & $(0.93-1.47)$ & 1.19 & $(1.02-1.38)^{*}$ & 1.63 & $(1.07-2.49)^{*}$ \\
\hline 3rd quintile & 1.07 & $(0.98-1.17)$ & 1.23 & $(0.98-1.54)$ & 1.13 & $(0.97-1.31)$ & 2.00 & $(1.34-3.00)^{* * *}$ \\
\hline 2nd quintile & 1.10 & $(1.00-1.21)^{*}$ & 1.07 & $(0.85-1.35)$ & 1.21 & $(1.04-1.40)^{*}$ & 1.58 & $(1.04-2.39)^{*}$ \\
\hline 1st quintile (lowest) & 1.34 & $(1.22-1.47)^{* * *}$ & 1.81 & $(1.46-2.24)^{* * *}$ & 1.40 & $(1.21-1.63)^{* * *}$ & 2.47 & $(1.68-3.65)^{* * *}$ \\
\hline
\end{tabular}

Outcome variables of multiple logistic regression were psychological distress and depression treatment. Psychological distress was measured by K6 (cut-off $=5$ or 13) and psychological complaints (general fatigue, sleeplessness, and/or irritation)

$a O R$ odds ratio adjusted for age and all other variables, $C I$ confidence interval

$* p<0.05, * * p<0.01, * * * p<0.001$ 
categories had a significantly higher aOR when compared with the 5th (highest) quintile, although there was no clear gradient in this relationship.

Table 4 shows cross-tabulations for depression treatment and explanatory variables in subjects with psychological distress. There were no significant differences in the prevalence of depression treatment between men and women. As to marital status, the highest prevalence was found in those who were separated/divorced and, as regards work, in the unemployed, for all three measures. As to household income, the highest quintile had the lowest prevalence and the lowest quintile had the highest prevalence; however, there was no clear gradient from the 2nd through 4th quintiles.

The results of multiple logistic regression analysis for depression treatment are shown in Table 5. All three measurements of psychological distress showed similar tendencies. Never married and separated/divorced respondents showed significantly higher aORs than the married respondents. There was no difference between employment and housework with employment, but significantly higher aORs were observed for other employment categories. As to household income, aORs in the 4th, 3rd, and 1st (lowest) quintiles were significantly higher than that in the 5th (highest) quintile.
Table 6 shows the prevalence of psychological distress among those who received depression treatment. In psychological distress measured by $\mathrm{K} 6$, the highest income quintile showed the lowest prevalence. For the 1st (lowest) through 4th income quintiles, aORs ranged from 1.33 to 2.14 compared to the 5th (highest) quintile, but did not reach statistical significance.

\section{Discussion}

This study, using a national sample, examined the relationship of psychological distress with SES, mainly in terms of household income and employment arrangement. The main findings were that: (1) lower income and unemployment were associated with a higher prevalence of psychological distress and depression treatment; (2) the association of income with psychological distress and depression treatment was not a dose-response relationship, but, rather, took a threshold form; and (3) higher income and employment were related to a lower prevalence of medical treatment in respondents with psychological distress.

The finding in this study that lower income was associated with a higher prevalence of psychological distress is

Table 4 Prevalence of depression treatment in subjects with psychological distress

\begin{tabular}{|c|c|c|c|c|c|c|}
\hline \multirow[t]{2}{*}{ Variable } & \multicolumn{2}{|c|}{ K6 5+ } & \multicolumn{2}{|c|}{ K6 13+ } & \multicolumn{2}{|c|}{ Psychological complaint } \\
\hline & Total & Treatment $(\%)$ & Total & Treatment $(\%)$ & Total & Treatment $(\%)$ \\
\hline \multicolumn{7}{|l|}{ Sex } \\
\hline Male & 3,247 & $132(4.1)$ & 416 & $61(14.7)$ & 913 & $81(8.9)$ \\
\hline Female & 3,682 & 169 (4.6) & 526 & $78(14.8)$ & 1,241 & $112(9.0)$ \\
\hline \multicolumn{7}{|l|}{ Marital status } \\
\hline Married & 4,773 & $157(3.3) * * *$ & 590 & $66(11.2)^{* * *}$ & 1,478 & $102(6.9)^{* * *}$ \\
\hline Never married & 1,593 & $104(6.5)$ & 254 & $49(19.3)$ & 485 & $59(12.2)$ \\
\hline Separated/divorced & 563 & $40(7.1)$ & 98 & $24(24.5)$ & 191 & $32(16.8)$ \\
\hline \multicolumn{7}{|l|}{ Employment arrangement } \\
\hline Employed (mainly working) & 4,745 & $146(3.1)^{* * *}$ & 604 & $66(10.9) * * *$ & 1,402 & $92(6.6)^{* * *}$ \\
\hline Housework with employment & 692 & $15(2.2)$ & 83 & $7(8.4)$ & 211 & $10(4.7)$ \\
\hline Housework without employment & 964 & $60(6.2)$ & 141 & $27(19.1)$ & 360 & $39(10.8)$ \\
\hline Unemployed & 404 & $68(16.8)$ & 93 & $36(38.7)$ & 138 & $42(30.4)$ \\
\hline Others & 124 & $12(9.7)$ & 21 & $3(14.3)$ & 43 & $10(23.3)$ \\
\hline \multicolumn{7}{|l|}{ Household income } \\
\hline 5th quintile (highest) & 1,257 & $26(2.1)^{* * *}$ & 141 & $8(5.7)^{* *}$ & 356 & $17(4.8)^{* * *}$ \\
\hline 4th quintile & 1,308 & $47(3.6)$ & 163 & $23(14.1)$ & 416 & $35(8.4)$ \\
\hline 3rd quintile & 1,339 & $59(4.4)$ & 178 & $27(15.2)$ & 407 & $30(7.4)$ \\
\hline 2nd quintile & 1,372 & $51(3.7)$ & 160 & $22(13.8)$ & 436 & $35(8.0)$ \\
\hline 1st quintile (lowest) & 1,653 & $118(7.1)$ & 300 & $59(19.7)$ & 539 & $76(14.1)$ \\
\hline
\end{tabular}

Treatment $(\%)$ is the percentage of the subjects with psychological distress among those who received depression treatment. Psychological distress was measured by K6 (cut-off $=5$ or 13) and psychological complaints (general fatigue, sleeplessness, and/or irritation)

$* * p<0.01, * * * p<0.001\left(\chi^{2}\right.$ test $)$ 
Table 5 Results of multiple logistic regression analysis for depression treatment in subjects with psychological distress

\begin{tabular}{|c|c|c|c|c|c|c|}
\hline \multirow[t]{2}{*}{ Variables } & \multicolumn{2}{|c|}{ Treatment/K6 5+ } & \multicolumn{2}{|c|}{ Treatment/K6 13+ } & \multicolumn{2}{|c|}{ Treatment/psychological complaints } \\
\hline & $\mathrm{aOR}$ & $(95 \% \mathrm{CI})$ & $\mathrm{aOR}$ & $(95 \% \mathrm{CI})$ & $\mathrm{aOR}$ & $(95 \% \mathrm{CI})$ \\
\hline Sex: female/male & 1.09 & $(0.82-1.43)$ & 0.94 & $(0.60-1.46)$ & 0.95 & $(0.66-1.36)$ \\
\hline \multicolumn{7}{|l|}{ Marital status } \\
\hline Married & 1.00 & Reference & 1.00 & Reference & 1.00 & Reference \\
\hline Never married & 1.54 & $(1.11-2.12)^{* *}$ & 1.39 & $(0.82-2.34)$ & 1.21 & $(0.79-1.84)$ \\
\hline Separated/divorced & 1.62 & $(1.09-2.42)^{*}$ & 2.15 & $(1.18-3.94)^{*}$ & 1.90 & $(1.15-3.12)^{*}$ \\
\hline \multicolumn{7}{|l|}{ Employment arrangement } \\
\hline Employed (mainly working) & 1.00 & Reference & 1.00 & Reference & 1.00 & Reference \\
\hline Housework with employment & 0.76 & $(0.43-1.33)$ & 0.85 & $(0.36-2.01)$ & 0.79 & $(0.39-1.61)$ \\
\hline Housework without employment & 2.18 & $(1.51-3.12)^{* * *}$ & 2.20 & $(1.24-3.90)^{* *}$ & 1.95 & $(1.23-3.10)^{* *}$ \\
\hline Unemployed & 4.70 & $(3.37-6.55)^{* * *}$ & 4.17 & $(2.46-7.08)^{* * *}$ & 4.89 & $(3.10-7.72)^{* * *}$ \\
\hline Others & 2.92 & $(1.56-5.47)^{* * *}$ & 1.16 & $(0.32-4.17)$ & 3.91 & $(1.84-8.34)^{* * *}$ \\
\hline \multicolumn{7}{|l|}{ Household income } \\
\hline 5th quintile (highest) & 1.00 & Reference & 1.00 & Reference & 1.00 & Reference \\
\hline 4th quintile & 1.69 & $(1.04-2.76)^{*}$ & 2.53 & $(1.08-5.94)^{*}$ & 1.86 & $(1.01-3.41)^{*}$ \\
\hline 3rd quintile & 1.95 & $(1.22-3.13)^{* *}$ & 2.71 & $(1.17-6.25)^{*}$ & 1.43 & $(0.76-2.67)$ \\
\hline 2nd quintile & 1.51 & $(0.93-2.45)$ & 2.11 & $(0.89-5.00)$ & 1.45 & $(0.79-2.67)$ \\
\hline 1st quintile (lowest) & 2.19 & $(1.39-3.45)^{* * *}$ & 2.40 & $(1.07-5.38)^{*}$ & 2.02 & $(1.13-3.60)^{*}$ \\
\hline
\end{tabular}

The outcome variable of multiple logistic regression was depression treatment. The analysis subjects had psychological distress measured by K6 (cut-off $=5$ or 13) and psychological complaints (general fatigue, sleeplessness, and/or irritation)

$a O R$ odds ratio adjusted for age and all other variables

$* p<0.05, * * p<0.01, * * * p<0.001$

Table 6 Psychological distress in subjects with depression treatment: prevalence and results of multiple logistic regression analysis

\begin{tabular}{|c|c|c|c|c|c|c|c|c|c|c|}
\hline \multirow[t]{2}{*}{ Household income } & \multirow[t]{2}{*}{ Total $N$} & \multicolumn{3}{|c|}{ K6 5+/treatment } & \multicolumn{3}{|c|}{ K6 13+/treatment } & \multicolumn{3}{|c|}{ Psychological complaints/treatment } \\
\hline & & $\%$ & $\mathrm{aOR}$ & $(95 \% \mathrm{CI})$ & $\%$ & $\mathrm{aOR}$ & $(95 \% \mathrm{CI})$ & $\%$ & $\mathrm{aOR}$ & $(95 \% \mathrm{CI})$ \\
\hline 5th quintile (highest) & 35 & 74.3 & 1.00 & Reference & 22.9 & & Reference & 48.6 & & Reference \\
\hline 4th quintile & 59 & 79.7 & 1.52 & $(0.55-4.19)$ & 39.0 & 2.14 & $(0.82-5.60)$ & 59.3 & 1.84 & $(0.77-4.37)$ \\
\hline 3rd quintile & 77 & 76.6 & 1.33 & $(0.51-3.48)$ & 35.1 & 1.67 & $(0.65-4.27)$ & 39.0 & 0.72 & $(0.31-1.66)$ \\
\hline 2nd quintile & 65 & 78.5 & 1.38 & $(0.51-3.76)$ & 33.8 & 1.60 & $(0.61-4.22)$ & 53.8 & 1.44 & $(0.61-3.41)$ \\
\hline 1st quintile (lowest) & 142 & 83.1 & 1.96 & $(0.74-5.19)$ & 41.5 & 2.02 & $(0.81-5.07)$ & 53.5 & 1.34 & $(0.59-3.03)$ \\
\hline
\end{tabular}

Outcome variables of multiple logistic regression analysis were psychological distress measured by K6 (cut-off $=5$ or 13) and psychological complaints (general fatigue, sleeplessness, and/or irritation). The analysis subjects received depression treatment

$a O R$ odds ratio adjusted for age, sex, marital status, and employment

in line with previous studies in which the association was generally dose-responsive $[12-14,20]$. In this study, however, the association appeared to show a threshold. All but the lowest quintile had similar prevalences of psychological distress. The cut-off of the lowest quintile was 3.6 million yen, which was almost half of the mean household income of the entire study subject population (7.4 million yen). This could mean that the lowest quintile of the population lives in relative poverty and is thus particularly vulnerable to psychological distress.

Concerning employment arrangement, this study showed unemployment to be associated with a higher prevalence of psychological distress, especially severe distress (K16 13+), and depression treatment. In the national data, unemployment is associated with higher mortality from suicide than any particular type of occupation [21]. It is suggested that unemployed people have specific needs for the prevention of psychological distress and suicide. The associations between psychological outcomes, income, and employment arrangement are probably interactive: lower income and unemployment result in psychological distress, and in turn psychological distress results in unemployment and decreased income. For this vulnerable population with lower incomes and unemployment, specific interventions aimed at 
both the medical treatment of psychological distress and social support for income and employment are needed.

Lower income was related to a higher rate of depression treatment. This relationship occurred not only because there was a higher prevalence of psychological distress in the lower-income population, but also because the higherincome population had a lower prevalence of depression treatment even if they had psychological distress. Interestingly, the relationship was not dose-responsive; the three middle-income quintiles had similar prevalences of depression treatment, while the lowest-income quintile had a markedly higher prevalence of treatment and the highest quintile had a markedly lower prevalence of treatment.

In most studies in other countries, lower income or lower educational attainment was associated with a lower prevalence of depression treatment, or there was no association [22-26]. In the present study, however, the lowestincome quintile showed the highest rate of depression treatment among respondents with psychological distress. Although there is generally a barrier to medical treatment for the lower-income population, particularly in the United States, which lacks nationalized health care $[24,25]$, in Japan this barrier appears to be relatively low due to the universal coverage of health insurance.

The finding that the highest-income quintile had a markedly lower rate of depression treatment among respondents with psychological distress raises two contrasting possibilities. The optimistic speculation is that distress in higher-income people with depression treatment is well controlled, and therefore their psychological distress is eased. Reports from other countries that people with higher SES are likely to receive more appropriate care are in line with this speculation $[27,28]$. The lower, though not statistically significant, prevalence of psychological distress in the higher-income population, as shown in Table 6, may support this hypothesis.

On the other hand, the more pessimistic speculation is that people with higher income or more demanding work may now simply endure psychological distress, being reluctant to consult professionals about their psychological problems. We speculate that high-income individuals may also face barriers to receiving consultations, such as difficulty in taking time off from work, and the social stigma of seeking mental healthcare when in a high-pressure job. In addition, it might be difficult to continue to work or to earn a high income while receiving psychological treatment. These situations may prevent the early treatment of psychological distress and result in deterioration of mental conditions, absence from work, job loss, and, in extreme cases, suicide. To summarize our results and speculations, people with higher incomes are less likely to have psychological problems, but face more difficulty obtaining treatments when they do suffer these afflictions. Because this study was cross-sectional, it cannot be concluded which possibility, the optimistic or the pessimistic, is predominant.

This study has several limitations. Because it was crosssectional, the results must be carefully interpreted. As mentioned above, the higher prevalence of psychological distress in the lower-income and unemployed populations might be the result of reverse causation, i.e., psychological distress causes lower income and unemployment. Reverse causation might also have an influence on the lower prevalence of depression treatment in the higher-income population. Another limitation is self-reporting in the questionnaire, in which medical treatment might have been under-reported, and there might have been reporting bias according to SES characteristics. Finally, household income was not adjusted for household size. However, a previous study has demonstrated that non-standardized income is as valid as standardized income for research purposes [29].

The results of this study have a few policy implications. First, the lower-income population, especially the population living in relative poverty, may have particular needs for the prevention of psychological distress. Their possible needs include not only mental health support, but also social support for socioeconomic factors, including income and job security. Second, populations other than the lowest-income quintile have similar risks of psychological distress, and thus require mental health support to some degree, regardless of income level, in order to prevent psychological distress and consequent job loss and income decrease. Finally, our results suggest that the population with higher income and full-time work may need suitable social environment arrangements to reduce barriers to obtaining medical treatment and professional support. Working conditions in which sources of psychological distress are decreased and employees are able to work without unreasonable psychological distress are required. Various mental health interventions should be comprehensively implemented, with the consideration of specific needs arising from all socioeconomic strata of the population.

Acknowledgments The present study was supported by a Grant-inAid for Scientific Research on Innovative Areas (Research in a Proposed Research Area) 2010 (No. 4102-21119003) from the Ministry of Education, Culture, Sports, Science and Technology, Japan.

\section{References}

1. Ustun TB, Ayuso-Mateos JL, Chatterji S, Mathers C, Murray CJ. Global burden of depressive disorders in the year 2000. Br J Psychiatry. 2004;184:386-92.

2. Ministry of Health, Labour, and Welfare. The vital statistics. Tokyo: Ministry of Health, Labour and Welfare; 2009. 
3. Nakao M, Takeuchi T. The suicide epidemic in Japan and strategies of depression screening for its prevention. Bull World Health Organ. 2006;84:492-3.

4. Yamada M. Depression and suicide prevention. Nippon Rinsho. 2007;65:1675-8. (in Japanese).

5. Fujino Y, Horie S, Hoshuyama T, Tsutsui T, Tanaka Y. A systematic review of working hours and mental health burden. Sangyo Eiseigaku Zasshi. 2006;48(4):87-97.

6. Kondo N, Subramanian SV, Kawachi I, Takeda Y, Yamagata Z. Economic recession and health inequalities in Japan: analysis with a national sample, 1986-2001. J Epidemiol Community Health. 2008;62:869-75.

7. Berkman LF. Social epidemiology: social determinants of health in the United States: are we losing ground? Annu Rev Public Health. 2009;30:27-41.

8. Theorell T. Working conditions and health. In: Berkman LF, Kawachi I, editors. Social epidemiology. Oxford: Oxford University Press; 2000. p. 95-117.

9. Tsutsumi A. Occupational class and health inequality: a possible role of occupational stress. J Natl Inst Public Health. 2007;56: 76-82. (in Japanese).

10. Landsbergis PA, Schnall PL, Pickering TG, Warren K, Schwartz JE. Lower socioeconomic status among men in relation to the association between job strain and blood pressure. Scand J Work Environ Health. 2003;29:206-15.

11. Tsutsumi A, Kayaba K, Tsutsumi K, Igarashi M. Association between job strain and prevalence of hypertension: a cross sectional analysis in a Japanese working population with a wide range of occupations: the Jichi Medical School cohort study. Occup Environ Med. 2001;58:367-73.

12. Kuruvilla A, Jacob KS. Poverty, social stress and mental health. Indian J Med Res. 2007;126:273-8.

13. Lorant V, Deliege D, Eaton W, Robert A, Philippot P, Ansseau M. Socioeconomic inequalities in depression: a meta-analysis. Am J Epidemiol. 2003;157:98-112.

14. Muntaner C, Eaton WW, Miech R, O'Campo P. Socioeconomic position and major mental disorders. Epidemiol Rev. 2004;26:53-62.

15. Inoue A, Kawakami N. Interpersonal conflict and depression among Japanese workers with high or low socioeconomic status: findings from the Japan Work Stress and Health Cohort Study. Soc Sci Med. 2010;71:173-80.

16. Sakurai K, Kawakami N, Yamaoka K, Ishikawa H, Hashimoto H. The impact of subjective and objective social status on psychological distress among men and women in Japan. Soc Sci Med. 2010;70:1832-9.
17. Ministry of Health, Labour, and Welfare. Comprehensive Survey of the Living Conditions of People on Health and Welfare. 2009. http://www.mhlw.go.jp/toukei/list/20-19-1a.html (in Japanese).

18. Furukawa TA, Kawakami N, Saitoh M, Ono Y, Nakane Y, Nakamura Y, et al. The performance of the Japanese version of the K6 and K10 in the World Mental Health Survey Japan. Int J Methods Psychiatr Res. 2008;17:152-8.

19. Kessler RC, Andrews G, Colpe LJ, Hiripi E, Mroczek DK, Normand SL, Walters EE, Zaslavsky AM. Short screening scales to monitor population prevalences and trends in non-specific psychological distress. Psychol Med. 2002;32:959-76.

20. Inoue A, Kawakami N, Tsuchiya M, Sakurai K, Hashimoto H. Association of occupation, employment contract, and company size with mental health in a national representative sample of employees in Japan. J Occup Health. 2010;52:227-40.

21. Ministry of Health, Labour, and Welfare. Statistics of Suicide Death. 2005. http://www.mhlw.go.jp/toukei/saikin/hw/jinkou/tokusyu/ suicide04/ (in Japanese).

22. Grunebaum MF, Oquendo MA, Manly JJ. Depressive symptoms and antidepressant use in a random community sample of ethnically diverse, urban elder persons. J Affect Disord. 2008;105: 273-7.

23. Hamalainen J, Isometsa E, Sihvo S, Kiviruusu O, Pirkola S, Lonnqvist J. Treatment of major depressive disorder in the Finnish general population. Depress Anxiety. 2009;26:1049-59.

24. McAlpine DD, Mechanic D. Utilization of specialty mental health care among persons with severe mental illness: the roles of demographics, need, insurance, and risk. Health Serv Res. 2000;35: 277-92.

25. Olfson M, Marcus SC. National patterns in antidepressant medication treatment. Arch Gen Psychiatry. 2009;66:848-56.

26. Weich S, Nazareth I, Morgan L, King M. Treatment of depression in primary care. Socio-economic status, clinical need and receipt of treatment. Br J Psychiatry. 2007;191:164-9.

27. Friedman ES, Wisniewski SR, Gilmer W, Nierenberg AA, Rush AJ, Fava M, et al. Sociodemographic, clinical, and treatment characteristics associated with worsened depression during treatment with citalopram: results of the NIMH STAR*D trial. Depress Anxiety. 2009;26:612-21.

28. Warden D, Rush AJ, Wisniewski SR, Lesser IM, Thase ME, Balasubramani GK, et al. Income and attrition in the treatment of depression: a STAR*D report. Depress Anxiety. 2009;26:622-33.

29. Fukuda Y, Nakao H, Imai H. Different income information as an indicator for health inequality among Japanese adults. J Epidemiol. 2007;17:93-9. 